\title{
ВЫЯВЛЕНИЕ ФАКТОРОВ РАЗЛИЧИЯ КАДАСТРОВОЙ И РЫНОЧНОЙ СТОИМОСТИ НЕДВИЖИМОСТИ
}

\section{Анастасия Сергеевна Логинова}

Сибирский государственный университет геосистем и технологий, 630108, г. Новосибирск, ул. Плахотного, 10, обучающийся, тел. (960)951-46-76, e-mail: anasney@mail.ru

Стоимость относится к числу фундаментальных экономических категорий и не имеет единственного или даже хотя бы нескольких общепринятых определений. Стоимость ассоциируется, во-первых, с полезностью - способностью вещей удовлетворять благосостоянию или приносить удовлетворение - и выступает как мера ее полезности. По выражению К. Менгера, стоимость - «характеристика того, насколько важны для нас отдельные товары (или наборы товаров), когда мы осознали, что без владения этими товарами невозможно удовлетворить наши потребности». Кадастровая стоимость отличается от рыночной стоимости недвижимости по ряду факторов. Именно эти факторы мы и будем выявлять в своей статье. В связи с тем, что вопрос оценки стоимости недвижимости бесспорно актуален в современном мире, мы можем с точностью заявить что: кадастр недвижимости имеет большое значение для имущественных и земельных отношений, так как затрагивает различные отрасли юридической науки. Стоимость- это самый важный и опять же актуальный аспект при покупке или продаже недвижимости. Поэтому важно знать какие факторы на неё влияют. И на сколько кадастровая стоимость отличается от рыночной.

Ключевые слова: оценка недвижимости, кадастровая стоимость, рыночная стоимость, недвижимость, факторы, цена, взаимодействие стоимостей

\section{IDENTIFICATION OF FACTORS THAT DIFFER IN THE CADASTRAL AND MARKET VALUE OF REAL ESTATE}

\section{Anastasia S. Loginova}

Siberian State University of Geosystems and Technologies, 10, Plakhotnogo St., Novosibirsk, 630108, Russia, Student, phone: (960)951-46-76, e-mail: anasney@mail.ru

Cost is one of the fundamental economic categories and does not have a single or even several generally accepted definitions. Value is associated, first, with utility - the ability of things to satisfy well - being or bring satisfaction-and acts as a measure of its utility. In the words of K. Menger, cost is " a characteristic of how important individual goods (or sets of goods) are to us, when we realized that it is impossible to meet our needs without owning these goods." The cadastral value differs from the market value of real estate in a number of factors. It is these factors that we will identify in our article. Due to the fact that the issue of assessing the value of real estate is undoubtedly relevant in the modern world, we can state with accuracy that: the real estate cadastre is of great importance for property and land relations, as it affects various branches of legal science. Cost is the most important and again relevant aspect when buying or selling real estate. Therefore, it is important to know what factors affect it. And how much the cadastral value differs from the market value. The cadastral value of real estate is the value of a real estate object that is determined by conducting a state assessment primarily for calculating taxes.

Keywords: real estate valuation, cadastral value, market value, real estate, factors, price, interaction of values 
Целью данной работы является: выявить и проанализировать факторы, изза которых кадастровая стоимость гораздо дешевле рыночной на рынке недвижимости.

Поставленная нами цель подразумевает выполнение следующих задач:

- выявление целей расчета кадастровой стоимости недвижимости;

- выявление факторов, влияющих на кадастровую стоимость недвижимости;

- выявление факторов, влияющих на рыночную стоимость недвижимости;

- разбор отличий кадастровой стоимости от рыночной.

Во время подготовки к совершению сделок купли-продажи недвижимости важно понимать все нюансы, связанные с этим сегментом рыночных отношений.

Кадастровая стоимость недвижимости - это стоимость объекта недвижимости, устанавливаемая посредством проведения государственной оценки прежде всего для расчета налогов.

Проанализировав кадастровую стоимость недвижимости, мы выявили несколько самых главных факторов от которых зависит ценообразование кадастровой стоимости недвижимости: его площадь, целевое назначение объекта, материал, из которого построен объект, года постройки и сдачи в эксплуатацию, экономическая ситуация в регионе и т.д.

И это пожалуй, 5 самых главных факторов, выявленных нами в ходе анализа изменения цен на недвижимость.

Так же в ходе исследования мы выявили цели расчета кадастровой стоимости недвижимости:

- вычисление суммы налога на недвижимость;

- подсчет суммы налога в случае купли-продажи/аренды/обмена;

- оформление права наследования на недвижимость;

- определение цены при обмене данного объекта на эквивалентный;

- оформление договора дарения на недвижимость.

Ценообразование недвижимости - это деятельность субъектов по формированию цен объектов на рынке, в т.ч. путем их взаимодействия, основанная на объективных экономических законах спроса и предложения, ключевых принципах и структуре ценообразующих факторов.

Нами было выявлено, что на рынке недвижимости выделяются два ключевых принципа ценообразования:

- субъективный (субъектный) принцип - принцип, при котором в формировании цены наибольшее влияние оказывает субъект (собственник, продавец, агент), устанавливая цену, как «случайную» вносимую субъектом (собственником, продавцом, агентом и пр.) рынка величину, в соответствии со своими потребностями;

- принцип факторного ценообразования - принцип, при котором формирование цены связано с анализом характеристик самого объекта, сопоставлением с другими аналогичными объектами, представленными на рынке. 
Понятие «рыночная стоимость» знакомо всем еще со школьной скамьи. Однако, что оно означает относительно вопросов оценки недвижимости, знает не каждый.

Рыночная стоимость - это наиболее вероятная цена, по которой объект недвижимости будет реализован на рынке в конкурентных условиях. Проанализировав рыночную стоимость недвижимости, мы выявили несколько самых главных факторов, которые влияют на ценообразование.

Рыночная стоимость недвижимости зависит от: планировки, площади жилых помещений (без учета лоджий, балконов, кладовых), технического состояния инженерных систем (водоснабжение, вентиляция, электрика), ремонта, наличия мебели, расположения (район и инфраструктура), этаж.

В ходе опроса респондентов (70 человек) мы составили диаграмму, которая показывает степень влияния факторов рыночной стоимости при выборе недвижимости (рисунок).

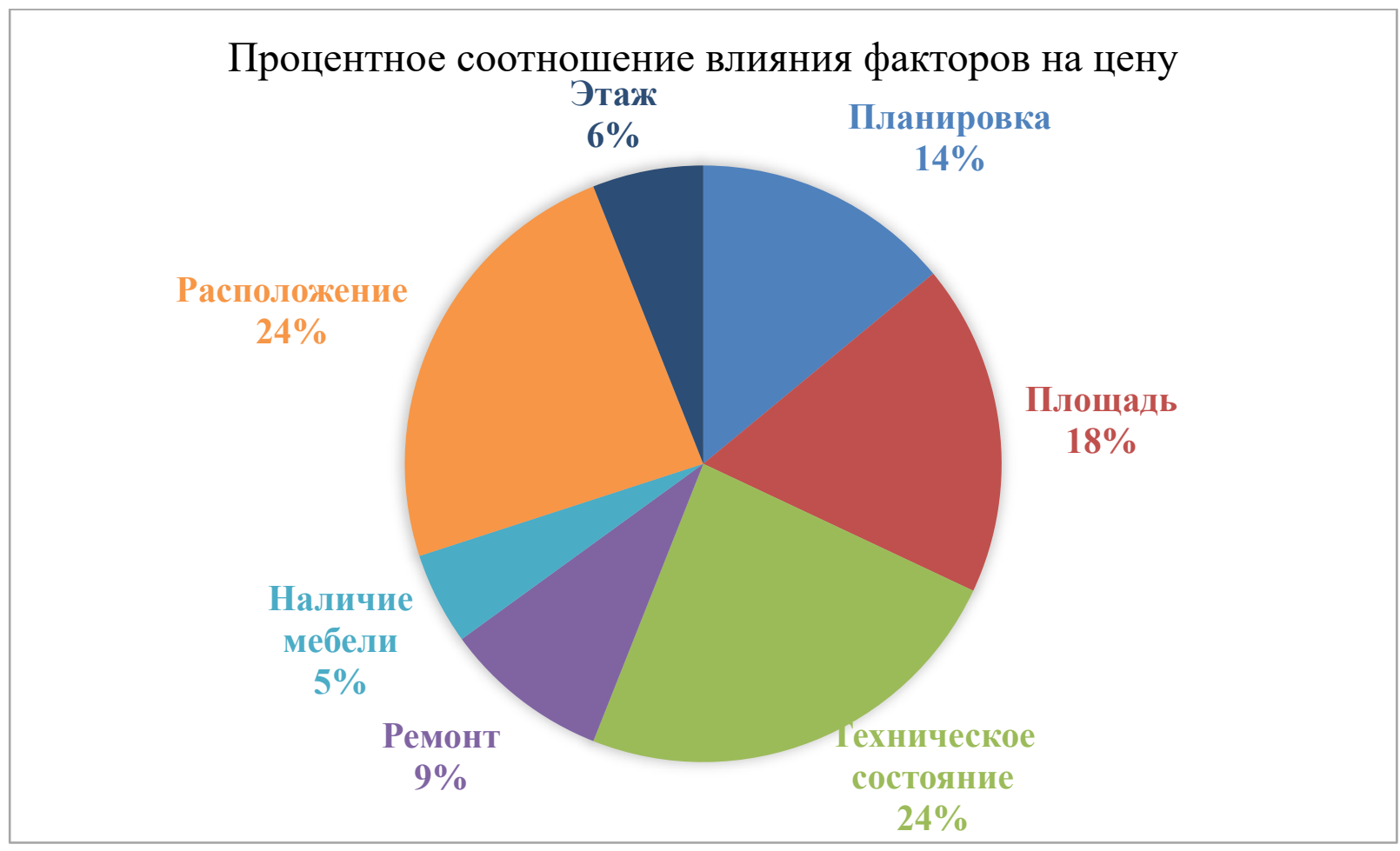

Диаграмма степени влияния факторов рыночной стоимости при выборе недвижимости

Исходя из рисунка можно сделать вывод, что больше всего при выборе недвижимости люди обращаю внимание на расположение недвижимости, на техническое состояние и на площадь недвижимости. Именно эти факторы больше всего и влияют на установление рыночной цены недвижимости.

Что касается взаимодействия двух видов стоимости, то здесь важно отметить, что кадастровая имеет значение при оценке рыночной стоимости, но в то же время не только не влияет на нее, а в некоторой степени опирается. 
Доказательством служит то, что при расчете кадастровой оценки специалисты берут во внимание цены на рынке недвижимости не по всей стране, а только в отдельно взятом регионе.

В ходе работы нами были сделаны следующие выводы:

- независимо от целевого назначения, вида разрешенного использования, и формы собственности на земельный участок, необходима кадастровая оценка стоимости недвижимости;

- кадастровая стоимость недвижимости заметно отличается от рыночной цены из-за многочисленных факторов;

- факторы кадастрового ценообразования значительно отличаются от факторов рыночного ценообразования.

\section{БИБЛИОГРАФИЧЕСКИЙ СПИСОК}

1. Экономика недвижимости в наше время: Исследования Новосибирской экономикосоциологической школы / Отв. ред. Т.И.Заславская, 3.И.Калугина. - Новосибирск: Наука, 1999, c. 51-90.

2. Барсукова С.Ю., Звягинцев В.И. Земельная реформа в России, или как в ходе ведомственных реорганизаций “реформировали” земельную реформу // Journal of Institutional Studies (Журнал институциональных исследований). 2015. Том 7, №2, с. 84-98.

3. Буздалов И. Н. Оценка недвижимости : взгляд сквозь призму замысла // АПК: экономика, управление, 2012, № 7, с. 3-17.

(C) А. С. Логинова, 2021 